\title{
AN IMPROVED INSERTION HEURISTIC FOR THE Euclidean Minimum Steiner Tree Problem
}

\author{
Ambrosch, K.; Humenberger, M. \& Kubinger, W.
}

Abstract: This Paper describes our current work on a novel hardware architecture for an embedded stereo vision system that is suitable for autonomous systems and service robots used in indoor environments. The architecture is based on two Digital Signal Processors (DSPS) for the pre- and post-processing as well as a Field Programmable Gate Array (FPGA) for stereo matching. For each processing stage the advantages of the selected platforms are discussed. For stereo matching FPGA and DSP implementations are compared and evaluated.

Key words: Stereo Vision, Embedded Systems, DSP, FPGA, Robotics
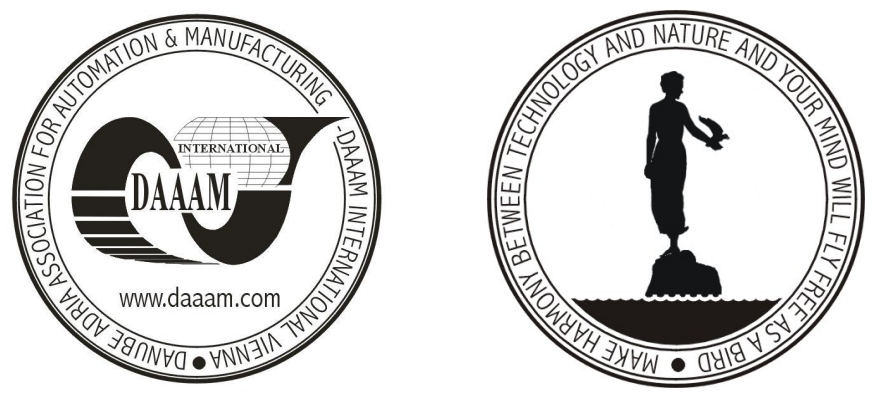

Authors' data: Dipl.-Ing. Ambrosch, K[ristian]; Dipl.-Ing. Humenberger, M[artin]; Dr. Kubinger, W[ilfried], Austrian Research Centers GmbH - ARC, Donau-City-Str. 1, A-1220 Vienna, Austria, kristian.ambrosch@arcs.ac.at, martin.humenberger@arcs.ac.at, wilfried.kubinger@arcs.ac.at

This Publication has to be referred as: Ambrosch, K.; Humenberger, M. \& Kubinger, W. (2007). Design Considerations for Embedded Stereo Vision Systems, Chapter 43 in DAAAM International Scientific Book 2007, B. Katalinic (Ed.), Published by DAAAM International, ISBN 3-901509-60-7, ISSN 1726-9687, Vienna, Austria

DOI: $10.2507 /$ daaam.scibook.2007.43 